$\mathrm{Cu}$ (II) Ion Catalytic Oxidation of $o$-Phenylenediamine and Diaminomaleonitrile and the Crystal Structure of the Final Products $\left(\mathrm{C}_{12} \mathrm{~N}_{4} \mathrm{H}_{11}\right)\left(\mathrm{ClO}_{4}\right)$ $\mathrm{H}_{2} \mathrm{O}$ and $\left[\mathrm{Cu}_{5}(\mathrm{CN})_{6}(\mathrm{dmf})_{4}\right]$

\section{SHIE-MING PENG*}

Department of Chemistry, National I'aiwan University, Taipei, Taiwan

\section{and DER-SHIN LIAW}

Institute of Chemistry, Academia Sinica, Nankang, Taiwan

Received September 12,1985

Transition metal complexes with highly delocalized, unsaturated, electron-rich ligands are of considerably interest, owing to their unusual properties. As a result of works on the first row transition metal complexes of s-bqdi, bqdi, s-disn and disn ligands [1-4], we report the reactions of $\mathrm{Cu}(\mathrm{II})$ ion with opda and damn, and the crystal structures of the final products, $\left(\mathrm{C}_{12} \mathrm{~N}_{4} \mathrm{H}_{11}\right)\left(\mathrm{ClO}_{4}\right) \mathrm{H}_{2} \mathrm{O}$ and $\left[\mathrm{Cu}_{5}\right.$ $\left.(\mathrm{CN})_{6}(\mathrm{dmf})_{4}\right]$.

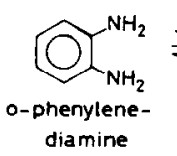

opda.

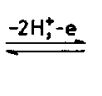

$$
\begin{aligned}
& \text { semi-o-benzoquinone- } \\
& \text { diimine }
\end{aligned}
$$

s-bqdi

1

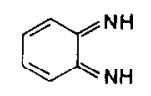

o-benzoquinone-

diimine

bqdi

2

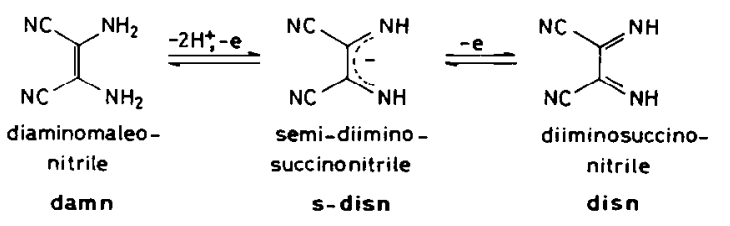

3
Reaction of the cupric chloride with opda in ammoniacal solution led to the isolation of the grey compound, 2,3-diaminophenazine, 5 .

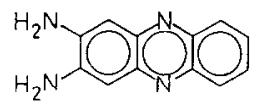

5

The violet crystalline compound [Cu(opda $\left.)_{2}\right]$ $\left(\mathrm{ClO}_{4}\right)_{2}$ was dissolved in $\mathrm{CH}_{3} \mathrm{CN}$ and oxidized by air immediately to give a dark green solution, which

*Author to whom correspondence should be addressed.

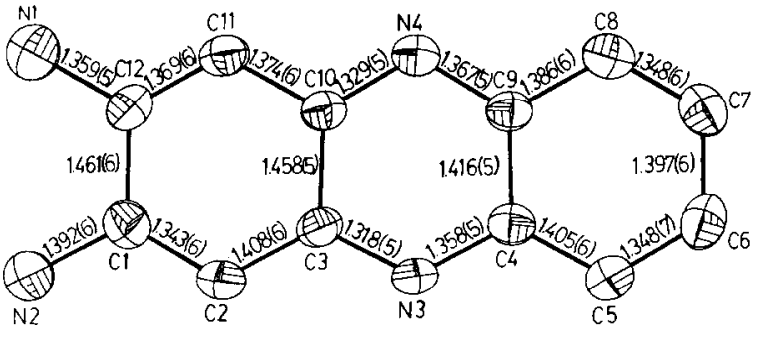

Fig. 1. ORTEP plot of the $\left(\mathrm{C}_{12} \mathrm{~N}_{4} \mathrm{H}_{11}\right)^{+}$cation. $P 2_{1} / n, a=$ $11.087(2), b=4.923(1), c=25.533(3) \AA, \beta=99.23(1)^{\circ} . Z=$ 4. 1534 reflections with $I>2 \sigma(I), 265$ parameters, $R=$ $0.056, R_{\mathrm{w}}=0.054$.

gradually became dark orange after a few days, when orange crystals suitable for single crystal X-ray analysis were deposited. The structure of the orange crystal, shown in Fig. 1, consists of a protonated 2,3-diaminophenazine cation, a perchlorate anion and a water molecule; the proton of the cation was found to be on the N4 atom. According to the contribution of six possible resonance forms of the cation, the $\pi$ bond strengths are as follows, if each resonance form is equally weighted. The observed bond pattern agrees very well with above $\pi$ bond strength.

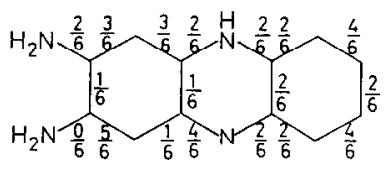

It has been reported [5] that $\left[\mathrm{Ni}(\mathrm{s}-\mathrm{bqdi})_{2}\right]^{+}$undergoes a disproportionation reaction to form 2,3diaminophenazine, 5. It is believed that the dark green species initially formed by air oxidation of [ $\left.\mathrm{Cu}(\text { opda })_{2}\right]\left(\mathrm{ClO}_{4}\right)_{2}$ in $\mathrm{CH}_{3} \mathrm{CN}$ is [Cu(s-bqdi) $)_{2}$ ] or a similar complex. Due to the high electron affinity of the $\mathrm{Cu}$ (II) ion, the $\mathrm{Cu}(\mathrm{II})$ ion might attract one electron from the s-bqdi ligand; this would initiate the disproportionation reaction. Because the solution is neutral or slightly acidic, the final product is protonated 2,3-diaminophenazine, 5 .

Yellow crystals were formed by reaction of the cupric acetate with damn in dmf solution for a few days. It was found later to have the composition of $\mathrm{Cu}_{5}(\mathrm{CN})_{6}(\mathrm{dmf})_{4}$ and the characteristic IR frequencies of $\nu_{\mathrm{C}-\mathrm{H}}: 2960 ; \nu_{\mathrm{C} \equiv \mathrm{N}}: 2156,2122 ; \nu_{\mathrm{C}=\mathrm{O}}$ : $1652 \mathrm{~cm}^{-1}$.

The crystal structure of $\left[\mathrm{Cu}_{5}(\mathrm{CN})_{6}(\mathrm{dmf})_{4}\right]$ has a number of unusual and interesting features. Firstly, it is obviously a mixed valence metal complex which contains both $\mathrm{Cu}(\mathrm{I})$ and $\mathrm{Cu}(\mathrm{II})$ ions: two $\mathrm{Cu}(\mathrm{I})$ ions with linear coordination, $\left[\mathrm{Cu}(\mathrm{CN})_{2}\right]$ (see Fig. 2a), the other two $\mathrm{Cu}(\mathrm{I})$ ions with distorted tetrahedral coordination $\left[\mathrm{Cu}(\mu-\mathrm{CN})(\mathrm{NC})_{2}\right]_{2}$ (Fig. $2 b$ ), and one 


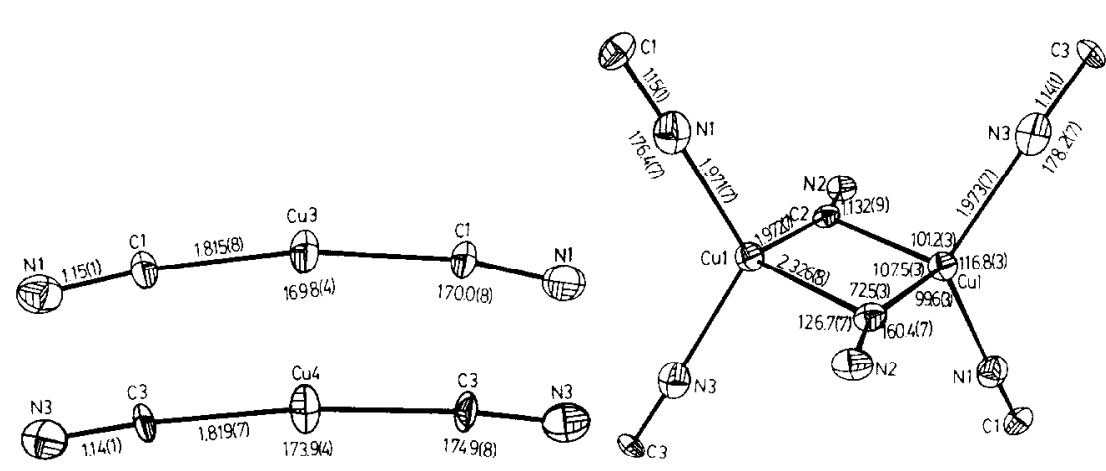

(a) (b)

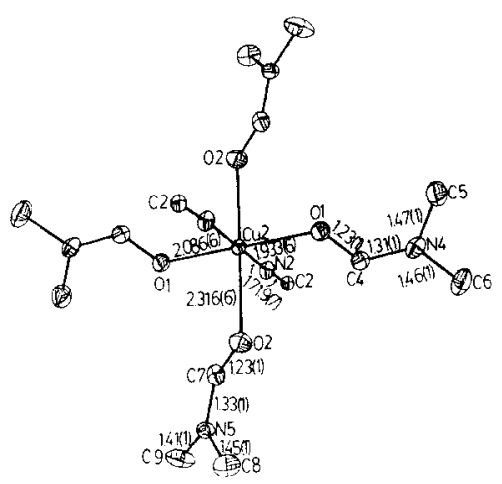

(c)

Fig. 2. ORTEP plot of the coordination sphere of the $\left[\mathrm{Cu}_{5}(\mathrm{CN})_{6}(\mathrm{dmf})_{4}\right]$ complex. $C 2 / c, a=14.034(4), b=12.591(3), c=$ $16.403(3) \AA, \beta=91.99(2)^{\circ} . Z=4.1270$ reflections with $I>3 \sigma(I), 227$ parameters, $R=0.039, R_{\mathrm{w}}=0.041$. The structure is a three-dimensional network with bridge cyanides. $\mathrm{Cu} 1$ is at general position, $\mathrm{Cu} 2$ is at inversion center, and $\mathrm{Cu} 3$ and $\mathrm{Cu} 4$ are at 2 fold axis. (2a) Coordination sphere of linear $\mathrm{Cu}(\mathrm{I})$ ions. (2b) Coordination sphere of distorted tetrahedral Cu(I) ions. (2c) Coordination sphere of distorted octahedral $\mathrm{Cu}(\mathrm{II})$ ion.

$\mathrm{Cu}(\mathrm{II})$ ion with distorted octahedral geometry [Cu$(\mathrm{NC})_{2}(\mathrm{dmf})_{4}$ ] (Fig. 2c). Secondly, the structure can be described as a 3-dimensional network with bridging cyanides. There are two types of $\mathrm{CN}$ bridges; one is a bidentate bridge [C1-N1, C3-N3] which connects the linear $\mathrm{Cu}(\mathrm{I})-\mathrm{Cu} 3, \mathrm{Cu} 4$ and the tetrahedral $\mathrm{Cu}(\mathrm{I})-\mathrm{Cu} 1$. The other is a tridentate bridge [C2-N2], which coordinates asymmetrically to two tetrahedral $\mathrm{Cu} 1$ ions through a carbon atom and to the octahedral $\mathrm{Cu} 2$ ion through a nitrogen atom. As far as we know, the tridentate $\mathrm{CN}$ bridge has not heen reported. Thirdly, the coexistence of the $\mathrm{Cu}$ (II) ion with the cyanide ion in this structure should be noted, since it is well known that the $\mathrm{Cu}(\mathrm{II})$ ion can oxidize the cyanide ion to form cyanogen [6]. The magnetic moment, 2.1 BM, and the $g$ values of the $\mathrm{Cu}$ (II) ion, 2.308, 2.174, 2.051, are consistent with the distorted octahedral geometry of the $\mathrm{Cu}$ (II) ion [7].

It is clear that the cyanide ion originates from the oxidation of damn through S-disn, disn, cyanogen intermediates. Such oxidations have been reported in the synthesis of $\left[\mathrm{Co}(\mathrm{CN})(\mathrm{s}-\mathrm{disn})_{2}\right]$ by the air oxidation of damn and $\mathrm{Co}(\mathrm{II})$ ion [1]. On the other hand, the HCN can be added to cyanogen to form disn, which is readily reduced to damn $[8,9]$. The reason why the $\left.[\mathrm{Cu} \text { (s-disn })_{2}\right]$ complex is unstable is attributed to the high electron affinity of $\mathrm{Cu}(\mathrm{II})$ ion, which will cause the further oxidation of the s-disn ligand.
The attempted isolation of reaction intermediates, $\mathrm{Cu}$ complexes of benzoquinonediimine or diiminosuccinonitrile, is currently being undertaken.

\section{Acknowledgements}

We thank the National Research Councils of Taiwan for support, and Prof. L. K. Liu and Prof. Y. Wang for valuable discussions.

\section{References}

1 S. M. Peng, Y. Wang, S. Wang, M. Chung, Y. Le Page and E. Gabe, J. Chem. Soc., Chem. Commun., 329 (1981). .

2 S. M. Peng, Y. Wang and C. K. Chiang, Acta Crystallogr., Sect. C. 40, 1541 (1984).

3 S. M. Peng, C. T. Chen, D. S. Liaw, C. I. Chen and Y. Wang, Inorg. Chim. Acta, 101, L31 (1985).

4 S. M. Peng, D. S. Liaw, Y. Wang and A. Simon, Angew: Chem., Int. Ed. Engl., 24, 210 (1985).

5 M. G. Miles and J. D. Wilson, Inorg. Chem., 14, 2357 (1975)

6 F. A. Cotton and G. Wilkinson, 'Advanced Inorganic Chemistry', Wiley, New York, 1980.

7 A. Abragam and B. Bleaney, 'Electron Paramagnetic Resonance of Transition Ions', Clarendon, Oxford, 1970.

8 R. E. Moser, J. M. Fritsch, T. L. Westman, R. M. Kliss and C. N. Matthews, J. Am. Chem. Soc., 89, 5673 (1967).

9 R. W. Begland, A. Cairncross, D. S. Donald, D. R. Hartter, W. A. Sheppard and O. W. Webster, J. Am. Chem. Soc., 93, 4953 (1971). 